\title{
GSS 2011 Linked with T1FF: Exploring the Cost of Child Care in Canada and the Use of the Child Care Expense Deduction
}

\author{
Leanne Findlay and Dafna Kohen
}

\begin{abstract}
Affordability of child care is fundamental to parents', in particular, women's decision to work. However, information on the cost of care in Canada is limited. The purpose of the current study was to examine the feasibility of using linked survey and administrative data to compare and contrast parent-reported child care costs based on two different sources of data. The linked file brings together data from the 2011 General Social Survey (GSS) and the annual tax files (TIFF) for the corresponding year (2010). Descriptive analyses were conducted to examine the socio-demographic and employment characteristics of respondents who reported using child care, and child care costs were compared. In 2011, parents who reported currently paying for child care (GSS) spent almost $\$ 6700$ per year ( $\$ 7,500$ for children age 5 and under). According to the tax files, individuals claimed just over $\$ 3900$ per year $(\$ 4,700)$. Approximately one in four individuals who reported child care costs on the GSS did not report any amount on their tax file; about four in ten who claimed child care on the tax file did not report any cost on the survey. Multivariate analyses suggested that individuals with a lower education, lower income, with Indigenous identity, and who were self-employed were less likely to make a tax claim despite reporting child care expenses on the GSS. Further examination of child care costs by province and by type of care are necessary, as is research to determine the most accurate way to measure and report child care costs.
\end{abstract}

Keywords: child development, affordability, early childhood, tax expense deduction, record linkage

Leanne Findlay, $\mathrm{PhD}$, is a Senior Social Science Researcher in the Health Analysis Division at Statistics Canada. Her areas of interest include using population health data to examine healthy child development, in particular via early learning experiences such as the child care environment. Recent publications include: Findlay, L. C., Beasley, E., Park, J., \& Kohen, D. (2018). Longitudinal child data: What can be gained by linking administrative data and cohort data? International Journal of Population Data Science. doi.org/10.23889/ijpds.v3i1.451; Findlay, L. C. (2017). Depression and suicidal ideation among young Canadians aged 15 to 24. Health Reports; Findlay, L. C., Kohen, D. E., Miller, A. (2014). Developmental milestones among Indigenous children in Canada. Paediatrics and Child Health, 19(5), 241-246. https://doi.org/10.1093/pch/19.5.241 
Dafna Kohen, PhD, is an Assistant Director and Researcher in the Health Analysis Division at Statistics Canada. Her areas of interest include using population health data to examine policy relevant issues for vulnerable populations including children and youth, people with activity limitations, and indigenous populations. Recent publications include: Arim, R. G., Miller, A. R., Kohen, D. E., Guèvremont, A., Lach, L. M., \& Brehaut, J. C. (2019). Changes in the health of mothers of children with neurodevelopmental disabilities: An administrative data study. Research in Developmental Disabilities, 86, 76-86. doi:10.1016/j.ridd.2018.12.007; Bélair, MA, Kohen, D.E., Kingsbury, M, \& Colman, I. (2018). Relationship between leisure time physical activity, sedentary behavior, and symptoms of depression and anxiety: Evidence from a population based sample of Canadian adolescents. BMJ open 2018;8:e021119.doi:10.1136/bmjopen-2017-021119; Arim, R.G., Guèvremont, A., Dahinten, V.S., \& Kohen, D.E. (2017). The use of administrative data to study the Triple P Positive Parenting Program. International Journal of Child, Youth, and Family Studies, 83 (3-4), 59-78.

Statistics Canada's commitment to data security

As part of our mandate, guaranteeing the security of sensitive statistical information within Statistics Canada is one of our top priorities.

1. Access to data for Statistics Canada employees requires justification and approval by senior management (Director and above). Employee access to data is also time bound and tracked.

2. Information technology (IT) environment is secure:

- access by Statistics Canada employees is controlled by user ID and security groups;

- access by employees is limited to variables they need;

- direct identifiers are only available to the few employees working to anonymize the data or conducting record linkages; and

- direct identifiers are always kept in separate files.

3. Based on confidentiality guidelines, only aggregate non-confidential data are released outside of Statistics Canada. Suppression or rounding rules are applied to the aggregate data to minimize risk of disclosure.

Statistics Canada's Executive Management Committee reviewed this project's proposal (\#052-2017) to conduct a linkage. A summary of the approved microdata linkage is posted on Statistics Canada's website, Statistics Canada's website. 


\section{Introduction}

"Affordability has been identified as a likely principle that will have a role in shaping child care policy across Canada" (Macdonald \& Friendly, 2016).

Child care is an important policy issue for families and society at large, not only for the developmental benefit of the youngest members of society, but also it provides opportunities for parents, in particular mothers, to participate in the labour force. However, availability and affordability of child care are fundamental to women's decision to take on employment (Lefebvre \& Merrigan, 2008; OECD, 2017; Fortin, 2017). Furthermore, child care options may contribute to the 'motherhood wage penalty' (Weeden, Cha \& Buuca, 2016), whereby women with children may be more apt to reduce work hours and less likely to travel or move for work or to prioritize their career due to (unpaid) family obligations. Since cost of care is a large determinant of parental employment decisions, and thus gender-based employment equity, the current study explores the cost of child care for families. Previous research has relied on parent-reported cost of child care (e.g., Sinha, 2014); however, this study will explore both survey-reported and administrative data (from tax files) to examine the merits and limitations of each to inform future work on child care costs in Canada.

Recent information on the cost of care in Canada is limited to a handful of reports. Findings from the 2011 General Social Survey on Families (Sinha, 2014) suggested that one in eight families (outside Quebec) had no direct cost of child care for children age 14 and under, with the median cost per month varying from $\$ 152$ per month in Quebec to $\$ 677$ per month in Ontario. Other studies have suggested similar amounts, with child care fees for young children costing up to one third of a women's total income (MacDonald \& Friendly, 2014), and fees being almost seven times higher in Ontario as compared to Quebec (Ferns \& Friendly, 2014) ${ }^{1}$. Despite large government financial contributions toward child care, often in the form of subsidy programs, the main source of funding is often parent fees. For instance, among families living in Ontario with at least one child 0 to 4 years old, the average family spends approximately one-quarter $(23.5 \%)$ of after-tax family income on child care (Cleveland, 2018). Although these studies provide basic information at the province and/or city level, there are several limitations including missing information on unregulated care, an inability to disentangle different aspects of that care (e.g., location, subsidies, type of care), and some studies being based on largely on urban care.

Child care costs may be supplemented by at least two different sources, both of which have limited eligibility. First, financial incentives such as tax expense deductions are one means by which governments can offset cost and increase participation in the child care market. Child care expenses can be claimed as a federal non-refundable expense deduction ${ }^{2}$ which allows taxpayers to reduce their payable taxes. Child care expenses are those expenses paid for someone to look after an eligible child ${ }^{3}$ in order for a parent to earn income from employment, run a business, attend

\footnotetext{
${ }^{1}$ Some provinces (e.g., Manitoba, PEI) have a maximum parent fee or cap on child care fees (Friendly et al., 2016).

${ }^{2}$ Non-refundable indicates that the tax payable is reduced by a certain amount. Individuals with no payable tax would not be eligible for the benefit, for example, individuals with less income than the basic personal amount $(\$ 10,382$ in 2010).

${ }^{3}$ An eligible child is one that lived with the tax filer when the expense was incurred, and was within the appropriate age range (i.e., 16 years of age or less).
} 
school, or conduct research. In 2010, the maximum claimable amount was $\$ 7,000$ for children born in 2004 or later, $\$ 4000$ for children born between 1994 and 2003, and $\$ 10,000$ for children born in 2010 or earlier and for whom the disability tax credit could be claimed ${ }^{4}$. Childcare expenses are generally claimed by the lower income earner (including a parent who earns no income). Eligible expenses include: licensed and unlicensed caregivers providing child care services; day nursery schools and daycare centres; educational institutions for the part of the fees that relate to child care services; day camps and day sports schools where the primary goal of the camp is to care for children; or boarding schools, overnight sports schools, or camps where lodging is involved.

Second, financial support for child care may be available from provincial or municipal organizations through subsidies. For example, in British Columbia, a new Affordable Child Care Benefit was implemented across the province in September, 2018 as a means to provide funding to assist families with the cost for care. In Ontario, subsidies are available through the provincial and municipal governments and First Nations communities. Parents can apply for full or partial subsidy based on such factors as residency, type of care, reason for care, special needs status and income (the amount paid is often determined by the family's adjusted net income). Finally, Quebec's unique child care model does not use a subsidy system but rather the province funds most regulated child care programs, making the parental contribution minimal (from $\$ 7.30$ per day up to $\$ 20$ per day, dependant on the level of household income). Although subsidies are an important source of funding for child care, administrative or parent-reported data on use and amount of child care subsidy information is sparse and not consistently reported by provinces and territories. Individual-level subsidy information would be useful to assess the extent to which families rely on subsidies, and how patterns of child care use differ by socio-demographic characteristics.

The purpose of the current study is to examine the feasibility of using linked survey and administrative data to compare and contrast parent-reported child care costs on the General Social Survey and information on parent's child care claim from tax information via the child care expense deduction. Survey-reported costs should be similar to what is claimed for tax purposes assuming that: 1) parents know and report an accurate estimate of incurred costs; 2) parents report child care expenses on their tax return; and 3) motivation to report accurately on both would be similar. It is possible that parents' reporting of child care expenses is higher than those from tax claims due to the maximum amount that can be reported as an expense deduction. An exploration of the characteristics of parents who claim the child care expense deduction will be performed and compared to those reporting child care costs in the GSS. This approach to studying child care costs will capitalize on extensive child care data and will be one of the first studies to explore the use of the child care expense deduction using tax-based information.

\footnotetext{
${ }^{4}$ These amounts were increased in 2014 for comparable age groups to $\$ 8,000, \$ 5,000$, and $\$ 11,000$.
} 


\section{Methods}

Data sources

Statistics Canada and other statistical agencies around the world are increasingly producing linked data files that combine survey information with administrative data. Administrative data are advantageous because they reduce response burden and survey collection costs, and also reduce recall or response bias particularly for sensitive information. The GSS-T1FF file brings together data from the 2011 General Social Survey (cycle 25) and the annual tax files (TIFF) from 1982 to 2013. More information on the linkage can be obtained from Statistics Canada (www.statcan.gc.ca/eng/sdle/index). This project will contribute to investigative work exploring the ways in which the GSS-T1FF file can be used to explore tax information, that is, to understand the use of the child care expense deduction in concert with a wealth of survey information on child care.

The 2011 General Social Survey on Families (GSS-2011) collected cross-sectional, retrospective information on the family life of Canadians. The target population included all persons 15 years of age and older in Canada, excluding residents of the Yukon, Northwest Territories, and Nunavut as well as full-time residents of institutions. The survey response rate was $65.8 \%$, resulting in a final sample of 22,435 participants. Results thus represent Canadians aged 15 and older living in the provinces. Of these respondents, 3,992 respondents had children who were of the age to use child care (less than 12 years of age) and were included in the current analyses. Among these, 2,071 individuals lived in households with working parents (both parents or only one parent in the case of single-parent homes). The unit of analysis for GSS is thus the parent (or household) and not the child.

The T1 Family File (T1FF) is an administrative data file constructed from personal tax files as well as the T4 annual employer records. The T1FF is constructed and maintained at Statistics Canada by the Income Statistics Division (ISD) for the purpose of estimating annual income among census families and individuals. T1FF years from 1982 to 2013 were linked to the 2011 GSS Families file, although for the current study, only the 2010 tax year was analysed as it aligned with the 12-month time frame for child care reporting in the GSS.

Measures

Descriptive characteristics. Socio-demographic characteristics of interest within the GSST1FF linked sample were: province of residence, marital status (single, married or common low, divorced or widowed), household income (less than $\$ 30,000^{5}, \$ 30,000-\$ 79,999, \$ 80,000$ $\$ 149,999$, and $\$ 150,000$ or higher), education level (Bachelor's degree or higher, high school or less than Bachelor's degree, and less then secondary school), and whether or not the person had Indigenous identity or was a visible minority.

Employment characteristics for both the respondent and their spouse included whether or not their main activity was working or in school, whether or not they had a job last week, and the type of job (paid employee versus self-employed). Four types of work were created: regular (i.e.,

\footnotetext{
${ }^{5}$ Sample size precluded a further breakdown of household income of less than $\$ 30,000$ per year.
} 
not contractual or anticipated termination date), seasonal (employment is intermittent according to the seasons of the year), term (set termination date), or casual or on call. Information on the number of hours worked per week was classified as less than 10, 10 to less than 20, 20 to less than 30, and 30 or more. Full time work is generally considered 30 or more hours per week (Goldin \& Mitchell, 2017). Finally, the work schedule was considered (i.e., a regular daytime schedule versus irregular including evening or night shift, rotating shift, and irregular schedule).

Child care. GSS respondents indicated whether or not they used any form of paid or unpaid child care and the total cost of care (per day, week, or month) for each child living in the household. ${ }^{6}$ Child care information based on a maximum of four children per household were considered in the current analyses because detailed child care information was not collected beyond four children (due to low frequencies). Summary variables were created to indicate whether or not the respondent had any children age 11 or less that had used child care in the past 12 months, and the total amount spent on child care. A variable was also created to identify cases in which there was at least one older child living in the household (age 12 to 18 years) who could potentially supervise and provide care for younger children if the parent(s) was not available.

Information from the 2010 tax year was also used to examine reported child care expenses. In the case of two parents, the person with the lower net income (including no income) is required to claim child care expenses unless they were a student (full time or part time) or were not capable of caring for children because of a mental or physical limitation or disability. In 2010, the maximum allowable expense was determined based on the child's age (born in 2004 or later, age 6 or younger the maximum was $\$ 7000$; born in 1994 to 2003, age 7 to $16, \$ 4000) .^{7}$ For more information, see Form T778 (Canada Revenue Agency).

From the linked file, parent-reported costs for child care, amount claimed for child care from the administrative tax information, and total maximum allowable expense (based on the number of children in the household and child age) were calculated ${ }^{8}$. Variables were also created to compare the parent-reported and tax claimed amounts to determine whether the parent-reported and tax claimed child care costs were the same amount, or which amount was higher. To discount negligible differences in the amounts as well as differences in estimation due to summer holidays, breaks in care, etc., a marker was created to indicate cases in which the difference was greater than $\$ 2,000$. It was also of interest to examine characteristics of those parents who reported child care expenses but did not claim any expenses on their tax claim, and vice versa.

\footnotetext{
${ }^{6}$ Information on type of care, location of care, and relationship between the child and the care provider was also collected. However, the current analyses combined across children to provide estimates for the parent respondent. It is possible for each child to be in a different type of care, rendering further analyses of these characteristics too complex for the present analysis.

${ }^{7}$ In the case of a child who has qualified for a disability tax certificate, this amount is increased to $\$ 10,000$. Disability status was not accounted for in the current project since the information is not available on the T1FF file.

${ }^{8}$ An examination of the characteristics of the sample in the GSS 2011 dataset compared to the GSS 2011-T1FF linked file is presented in Appendix A.
} 


\section{Analysis}

Descriptive analyses (frequencies and means) were conducted to examine the sociodemographic and employment characteristics of respondents who reported using child care. Respondents with at least one child aged 11 and under were included in the analyses, although a subset of those with children aged 0 to 5 years was also examined separately. Chi-square tests were performed to indicate significant differences in these characteristics based on whether or not the respondent reported using any child care. Of particular interest were households where both parents were working but did not report using child care. Thus, a subset of dual parent or single parent working respondents were examined separately to more closely examine employment characteristics and child care information; this included single parents who were working as well as dual parents where both parents were working.

Child care costs were compared for both the survey-reported and tax variables. Pearson correlations between the reported and claimed amounts were calculated, as well as proportions to compare the absolute values of survey-reported and tax-claimed amounts. The mean values as well as maximum claim amount are also reported.

Finally, the socio-demographic and employment characteristics of respondents who reported child care costs, but did or did not make a tax claim, were also explored. Descriptive analyses were conducted, and a multiple logistic regression was performed in order to examine whether or not any of the univariate associations remained significant after accounting for all other variables.

Survey sampling weights specifically created for the linked GSS-T1FF file were applied in order to make the results representative of the Canadian population. Bootstrap weights were applied using SUDAAN 11.0.1 to account for under-estimation of standard errors due to the complex survey design.

\section{Results}

\section{Characteristics of Child Care Users}

In $2011,54 \%$ of parents of children ages 0 to 11 reported that they had used child care for at least one child in the past year (59\% of parents of children ages 0-5). As would be expected, some differences in child care participation were shown by province, with $67 \%(74 \%)$ of parents in Quebec reporting having used child care compared to $41 \%(50 \%)$ of parents in Manitoba (see Table 1). Those who were married or common law were less likely to use child care than those who were single or divorced/widowed. Higher education was associated with a greater likelihood of reporting having used child care. Individuals with an Indigenous identity or who were a visible minority were less likely to report using child care.

In terms of work characteristics, employed people, in particular paid workers and those who had a regular job, were more likely to use child care as compared to those who were selfemployed and seasonal workers, respectively. Individuals who worked more than 30 hours per week (i.e., full time work) and who worked a regular schedule as compared to an irregular schedule such as shift work were slightly more likely to report using child care. A subsequent analysis 
examined the work characteristics of male and female respondents separately. Male respondents were more likely to work or be at school, to be a paid or a self-employed worker, to work a regular or seasonal job, and to work full time compared to female respondents. Females were more likely to be at home or on parental leave, to work a term or on-call type job, and to work part time. However, interactions with gender for child care analyses were not conducted since child care is used by both parents (i.e., is a characteristic of the household), and analyses would reflect the sex of the respondent and not necessarily trends in use among males and females.

Limiting the analyses to only those households in which all parents were working, 67\% used child care (76\% if there was a child age 5 or less). Table 2 demonstrates differences in child care use among those with different work characteristics specifically for two-parent households where both parents were working as well as single working parents. Paid workers and regular workers were more likely to use child care, both for the individual and their spouse, compared to self-employed and seasonal workers. Again, hours worked per week did not have a substantial impact on the use of child care, although individuals working more than $30 \mathrm{hrs}$ per week were the most likely to use child care. However, in households where there was an older child who was of age to watch their siblings (i.e., 12 years or older), $50 \%$ of parents reported using child care, as compared to $74 \%$ of parents that did not have an older sibling available for care ${ }^{9}$.

\section{Child Care Cost}

Information on the cost of care can be compared between the amount reported on the GSS and the tax-reported information from the linked T1FF (see Figure 1 and Table 3). Among those who reported paying for child care, individuals reported on the GSS that they spent almost $\$ 6700$ per year on child care (just over $\$ 7,500$ when children were age 5 and under), although based on the maximum eligibility criteria, they were estimated to be eligible to claim an average of $\$ 10,300$ $(\$ 12,000)$. Almost one quarter of respondents spent more than the maximum tax-eligible amount, suggesting that for these individuals, costs were higher than their eligible level of benefits (see Appendix for a breakdown by province). Further analyses ${ }^{10}$ suggested that individuals who reported more than the maximum tax-eligible amount were less likely to live in Quebec ${ }^{11}$, Manitoba or Saskatchewan (compared to Ontario), were more likely to have a higher household income, and were more likely to have a greater number of children in the household ${ }^{12}$.

\footnotetext{
${ }^{9}$ In the case where children were under the age of 5, having a sibling in the household only made a slight difference in child care usage. Where there was no sibling, $76 \%$ of individuals reported using child care, as compared to $72 \%$ of parents of children under age 5 when there was a sibling over the age of 12 .

${ }_{10}$ A multivariate model was performed predicting survey-reported amount being greater than the maximum by province, income, marital status, grouped number of hours worked, and the number of children in the household.

11 Some, but not all, families in Quebec may obtain child care through subsidized programming. Individuals are still eligible for federal (but not provincial) expense deductions.

12 Maximum tax-eligible amount accounts for the number of children in the household.
} 
Figure 1. Child care costs, per year

$$
14,000
$$

12,000

10,000

8,000

6,000

4,000

2,000

0

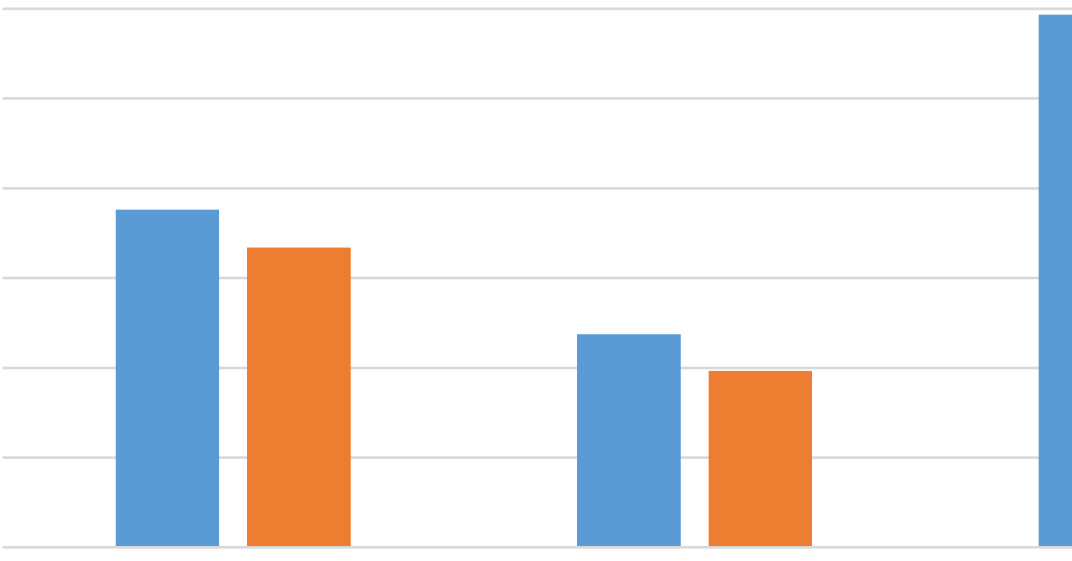

Self-report

Claimed
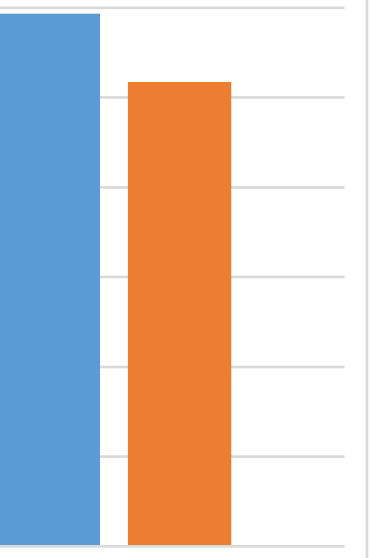

Maximum

Children 0-5 years

Children 0-11 years

Source: General Social Survey 2011-T1FF linked file, Statistics Canada

According to the tax files, on average, individuals claimed less than the mean eligibility limit at just over $\$ 3,900$ per year $(\$ 4,700)$. Only $9 \%$ of individuals with at least one child aged 0 11 years claimed the exact eligible amount (also 9\% among those with at least one child 0-5 years of age). Approximately one in four individuals with a child aged 0-11 years who reported child care costs on the GSS did not report any amount on their tax file; about four in ten who claimed child care on the tax file did not report any cost on the survey.

Comparing the values from the two sources of data (survey-reported and tax claimed amount), $71 \%$ of the time the survey amount was higher than the claimed amount, about $9 \%$ of the time the amount was the same, and $20 \%$ of the time the claimed amount was higher ${ }^{13}$. Four out of ten times, the difference between the survey-reported amount and the claimed amount was more than $\$ 2000$ per year. It is possible that individuals over-estimated the amount that they spend when they report costs on a survey as compared to when they file taxes (when they may be using a receipt to report the value of child care paid). Further analyses suggested that parents who reported the GSS amount based on a monthly amount (as opposed to amount per week or per year) were more likely to have a higher survey-reported cost of child care.

\footnotetext{
${ }^{13}$ Zeros were excluded from the analysis.
} 
Our final analysis examined differences in the socio-demographic or work characteristics of individuals who reported a cost of child care on the survey and did or did not make a tax claim ${ }^{14}$. As shown in Table 4, individuals were more likely to report a tax claim if they were a male survey respondent ( $81 \%$ as compared to $73 \%$ of females). Individuals who were married or common-law were also more likely to make a tax claim, as were those with a higher level of education and higher income. Those with Indigenous identity or who were a visible minority were less likely to claim child care expenses on their tax return. In terms of work characteristics, paid workers were much more likely to make a tax claim that those who were self-employed (who were also shown to be less likely to use child care). More than four out of five (81\%) of those with a regular schedule made a tax claim for child care expenses, as compared to three out of four (72\%) of those with an irregular schedule such as working nights or rotating shift (who were also generally less likely to use care).

A multiple logistic regression that considered demographic and work characteristics simultaneously suggested that many of these variables were independently associated with not claiming child care expenses. Respondents who were female, with a lower education, lower income, with Indigenous identity, and who were self-employed were less likely to make a tax claim although they had reported child care expenses on the survey. In contrast, income, visible minority status, and work schedule were no longer significant once all factors were considered simultaneously.

\section{Discussion}

As part of our understanding on how families balance care for their young children and participation in the workforce, the objective of the current study was to examine the cost of child care using two sources of information - survey reported child care cost, and the amount reported on for tax expense deduction purposes. While not all women chose to return to the work force after having children, cost of child care is a particularly important issue for women who may negotiate employment based on child rearing decisions (Lefebvre \& Merrigan, 2008; Fortin, 2017). This study does not consider the lower income of women or families who select to stay at home after the birth of a child based on preferences. However, it does explore the employment characteristics of women who are working and thus potentially need child care to care for the child while parents are unavailable for care. A unique aspect of this study was examining child care costs using both survey and administrative tax information. The final goal was to examine the demographic and work characteristics of individuals who reported child care costs on the survey but did not claim an expense deduction for those costs on their tax return.

According to data collected on the GSS in 2011, approximately half (54\%) of parents of children ages 0 to 11 reported that they had used child care for at least one child in the past year (59\% of parents with children ages 0 to 5 years). As expected, parents in Quebec were the most likely to report having used child care, as were individuals who were married or common law,

\footnotetext{
${ }^{14} \mathrm{Few}$ differences were found in the characteristics of people who claimed child care expenses but did not report any child care cost on the survey.
} 
with a higher education, and higher income. Previous studies have also suggested that uptake of child care is highest in Quebec compared to other provinces (Kohen et al., 2008; Fortin, 2017; Friendly et al., 2016) and that individuals with greater socio-economic means are more likely to need and use care (Petitclerc et al., 2017).

Turning to work characteristics, women were less likely to work, more likely to work an irregular schedule, and more likely to work part-time. In contrast, paid workers and those who had a regular job, compared to those who were self-employed and seasonal workers, were more likely to use child care, as were those who worked a regular schedule as compared to an irregular schedule such as shift work. From a gender-based perspective, it is possible that women in nonstandard work arrangements are those who are less likely to use care because of difficulties finding suitable child care. This aligns with information to suggest that it is difficult to obtain child care for shift or irregular work hours (Scotland et al., 2017). However, even in households in which parents were working more than 30 hours per week, about one third of respondents did not report using any child care. These parents were more likely to be self-employed and to work an irregular schedule, although it is also possible that they use other types of support (e.g., family care, multigenerational households). The results also suggest that working parents often rely on older siblings to care for their younger children since working parents were much less likely to report using child care if there was a sibling aged 12 and older to provide supervision at home. Again, this points to a need for flexible care arrangements that may be outside typical work hours or that can meet the needs of alternative work schedules that may not align with the standard work day/week.

A unique contribution of the current study is the ability to examine child care cost for families both from survey data as well as tax claim information. At the household level, survey respondents with at least one child age 11 and under reported spending approximately $\$ 6,700$ on child care in the past year ( $\$ 7,500$ among those with at least one child age 5 and under). However, according to the tax files, these same households claimed approximately $\$ 3,900(\$ 4,700)$, a much lower value. At the individual level, $71 \%$ of survey respondents reported an amount that was higher than the tax claim, about $9 \%$ of the time the amount was the same, and $20 \%$ of the time the tax claimed amount was higher. Four out of ten times, the difference between the survey-reported amount and the claimed amount was more than $\$ 2,000$ per year.

These findings suggest that there is a fairly large discrepancy between survey-reported child care costs and those obtained through tax files, with the trend being for higher amounts from the survey-reported information. At this time, it is unclear as to the reasons for this discrepancy. Parents base their tax claims on a receipt provided by the child care provider(s), making is easier to report exact amounts, whereas survey information is more likely to be subject to bias or inaccurate reported amounts. While it would be to the individuals' advantage to claim the full value paid, it is also possible that parents do not include all expenses paid when completing their tax or survey information (e.g., expenses incurred for alternative care, summer camps, after school activities, irregular babysitters, etc.), or that some individuals use care and do not request or receive a receipt. It is also possible that parents overestimate the actual amount paid for care when reporting on a daily, weekly, or monthly basis, which could be further overestimated when extrapolating to an annual amount. This was supported by the subsequent analyses that those who reported monthly costs were more likely to overestimate reported versus claimed child care expenses compared to those who reported weekly expenses. 
It could also be argued that obtaining child care costs from tax data are limited by the maximum amount that individuals can claim. Results from the current study would suggest that this does not explain the discrepancy. The theoretical maximum amount that each individual could claim was calculated based on the age and number of children in the household. From the survey data, only approximately one quarter of respondents reported spending more than the maximum amount that could be claimed. Interestingly, those individuals were more likely to have a higher household income (and thus have more disposable income to spend on child care). Overall, however, the mean child care cost was almost $\$ 3,000$ less than the mean maximum value eligible as an expense deduction.

Not all households reported both sources of child care costs - one quarter of those who reported child care costs on the survey did not claim any amount on their tax file and four in ten who claimed the expense deduction for child care did not report any cost on the survey. Our final objective was to explore the characteristics of individuals who reported child care costs and who did not make a tax claim in order to explore potential demographic or work characteristics that might help to explain why these individuals do not use the expense deduction for their child care expenses. Multivariate analyses suggested that individuals with a lower education, lower income, with Indigenous identity, and who were self-employed were less likely to make a tax claim despite reporting child care expenses on the GSS. It is possible that these individuals would not benefit from the child care expense deduction, for example, if their household income was lower than the base amount, or if their personal child care cost was relatively low and the claimed amount would not alter their tax owing (e.g., heavily subsidized care). These families may be more likely to use other types of care, for example, informal care by friends or family, or care arrangements that do not provide documentation necessary for tax purposes (e.g., receipts). Another possibility is that they are not aware of the child care expense deduction program, or that they are using child care subsidies which partially or fully covers the cost of care. Further research including qualitative studies may be necessary to examine why these individuals are less likely to be using the child care expense deduction program.

The current study is one of the first to explore the concordance between survey and taxbased child care costs, and is the most recent, nationally representative linked data available to address this question. However, several limitations should be acknowledged. As mentioned previously, self-reported data is subject to recall and reporting bias and may not provide an accurate estimate of costs incurred. However, tax-claimed amounts are also subject to reporting bias if individuals do not claim any amount, or do not fully report the amount paid for all child care expenses, or if those expenses exceed the maximum claimable amount. Tax claims must be made by the lower earning parent (including zero income). Furthermore, the focus of the GSS was on families, and not children, thus expenses (and the maximum claim amount) were combined for up to four children. More precise comparisons at the individual child level might reveal different findings. Also, GSS information reflects current child care situations, whereas tax data was for the preceding year. However, since the children were older and thus could have needed less care, this would suggest that the amount from tax data might be more, not less, than the survey value. It is possible that individuals are not currently using care (and thus have no cost), but did so in the previous year and thus have tax-eligible costs. Finally, given that the survey is cross-sectional in 
nature, all associations between child care costs and demographic and work characteristics should be viewed as correlations and not causal.

\section{Conclusions}

Affordability of child care is of paramount importance for families, in particular mothers', ability to participate in the labour force. Recent announcements around funding for child care frameworks and programming have brought the cost of child care to the forefront. The current study explored both survey and tax-based child care costs, the results of which suggesting that individuals report higher child care costs on a survey than what they claim for an expense deduction. However, it is unclear which of these two sources accurately estimates costs, and thus it is unclear whether survey or tax data provides a better estimate of child care costs. Furthermore, the findings suggest that there are many people (23\%) who report child care costs on a parentreported survey but do not claim any costs for an expense deduction and vice versa (42\%). Individuals with a lower education, lower income, with Indigenous identity, and who were selfemployed were less likely to make a tax claim despite reporting child care expenses on a survey. This might suggest that there are particular groups that are less likely to benefit from child care tax programs, or are using care that does not provide tax receipts needed to make such a claim. It is also possible that their income is so low that claiming an expense deduction would not be of any benefit, and thus they do not report child care expenses. Many other aspects that relate to child care cost are of issue for future research, including the extent to which the cost of child care contributes to women's decisions to stay at home to raise young children versus going back to work, comparability of cost across provinces and internationally, and the role and use of subsidies to understand why certain groups may or may not report child care costs (either on a survey or for an expense deduction). Further examination of how to best measure and report child care costs, be that on a survey or through administrative data, is necessary. This is particularly of interest for certain subgroups of the populations (e.g., low income, Indigenous) for whom policies such as the expense deduction may be targeted. 


\section{References}

Cleveland, (2018). Affordable for all: Making licensed child care affordable in Ontario. Cleveland Consulting: University of Toronto.

Ferns, C., \& Friendly, M. (2014). The state of early childhood education and care in Canada 2012. Moving Childcare Forward Project (a joint initiative of the Childcare Resource and Research Unit, Centre for Work, Families and Well-Being at the University of Guelph, and the Department of Sociology at the University of Manitoba). Toronto: Movingchildcareforward.ca

Friendly, M. Larsen, E., Feltham, L., Grady, B., Forer, B., \& Jones, B. (2018). Early childhood education and care in Canada, 2016. Childcare Resource and Research Unit.

Fortin, P. (2017). What Have Been the Effects of Quebec's Universal Childcare System on Women's Economic Security? Brief Submitted to the Standing Committee on the Status of Women (FEWO) of the House of Commons, Ottawa

Goldin, C., \& Mitchell, J. (2017). The new life cycle of women's employment: Disappearing humps, sagging middles, expanding tops. Journal of Economic Perspectives, 31 (1), 161182.

Lefebvre, P., \& Merrigan, P. (2008). Child-care policy and the labor supply of mothers with young children: A natural experiment from Canada. Journal of Labor Economics, 26(3), 519-548.

Lero, D. (2010). Canadian Data on Early Childhood Education and Care: Challenges and Opportunities. Unpublished paper.

Kohen, D. E., Dahinten, V. S., Khan, S., \& Hertzman, C. (2008). Child care in Quebec: A universal program. Canadian Journal of Public Health, 99(6), 451-455.

Macdonald, D. \& Friendly, M. (2014). The Parent Trap: Child care fees in Canada's big cities. Canadian Centre for Policy Alternatives.

Macdonald, D. \& Friendly, M. (2016). A growing concern: 2016 Child care fees in Canada's big cities. Canadian Centre for Policy Alternatives.

OECD Directorate for Education. (2017). Early childhood education and child care policy. Canada: country note.

Petitclerc, A., Côté, S., Doyle, O., Burchinal, M. Herba, C., Zachrisson, H.D.,...Raat, H. (2017). Who uses early childhood education and care services? Comparing socioeconomic selection across five western policy contexts. International Journal of Child Care and Education Policy, 11(3). DOI 10.1186/s40723-017-0028-8

Scotland, P. (2017). A community survey of child care issues in Canadian shift workers: Evidence for barriers and opportunities. International Journal of Child, Youth, and Family Studies, 8(1), 42-73.

Sinha, M. (2014). Child care in Canada. Statistics Canada Catalogue no. 89-652-X - No. 005

Weeden, K. A., Cha, Y., \& Buuca, M. (2016). Long work hours, part time work, and the trends in the gender gap in pay, the motherhood wage penalty, and the fatherhood wage premium. 
Table 1. Proportion of Canadian parents living in the provinces who use child care

\begin{tabular}{|c|c|c|c|c|c|c|}
\hline & & $\mathrm{N}$ & Weighted N & $\%$ & LOWER & UPPER \\
\hline \multicolumn{2}{|l|}{ Any child care } & 2228 & $3,038,585$ & 54.1 & 53.8 & 54.5 \\
\hline \multirow[t]{10}{*}{ Province } & Nfld/Lbd & 121 & 43,648 & 59.8 & 58.4 & 61.2 \\
\hline & PEI & 63 & 12,340 & 66.2 & 64.2 & 68.1 \\
\hline & Nova Scotia & 103 & 71,049 & 57.2 & 55.5 & 58.8 \\
\hline & New Brunswick & 115 & 69,279 & 61.2 & 59.6 & 62.9 \\
\hline & Quebec & 471 & 845,462 & 66.9 & 66.1 & 67.6 \\
\hline & Ontario & 596 & $1,120,897$ & 51.4 & 50.8 & 52.0 \\
\hline & Manitoba & 109 & 81,627 & 41.0 & 39.7 & 42.4 \\
\hline & Sask & 128 & 92,799 & 56.2 & 54.8 & 57.6 \\
\hline & Alberta & 304 & 330,708 & 45.9 & 45.1 & 46.7 \\
\hline & $\mathrm{BC}$ & 218 & 370,777 & 49.1 & 48.0 & 50.1 \\
\hline \multirow[t]{3}{*}{ Marital status } & Single & 178 & 164,254 & 58.9 & 57.3 & 60.4 \\
\hline & Married or common law & 1875 & $2,739,366$ & 53.5 & 53.1 & 53.9 \\
\hline & Divorced, widowed & 175 & 134,964 & 62.2 & 60.7 & 63.7 \\
\hline \multirow[t]{3}{*}{ Education } & Bachelor or higher & 847 & $1,169,143$ & 59.0 & 58.4 & 59.6 \\
\hline & $\begin{array}{l}\text { High school or less than } \\
\text { Bachelors }\end{array}$ & 1276 & $1,717,730$ & 54.0 & 53.5 & 54.5 \\
\hline & Less than secondary & 95 & 136,816 & 33.9 & 32.7 & 35.2 \\
\hline \multicolumn{2}{|c|}{ Indigenous identity } & 85 & 84,726 & 43.3 & 41.4 & 45.2 \\
\hline \multicolumn{2}{|c|}{ Visible minority } & 280 & 464,487 & 39.9 & 39.1 & 40.7 \\
\hline \multicolumn{2}{|c|}{ Respondent main activity is work or school } & 1821 & $2,475,153$ & 59.8 & 59.4 & 60.3 \\
\hline \multicolumn{2}{|c|}{ Respondent main activity is child care } & 255 & 354,105 & 36.9 & 36.1 & 37.7 \\
\hline \multicolumn{2}{|c|}{ Had a job or was self employed in the last week } & 1936 & $2,648,659$ & 59.7 & 59.3 & 60.1 \\
\hline \multirow[t]{2}{*}{ Type of job } & Paid worker & 1782 & $2,414,349$ & 60.2 & 59.8 & 60.6 \\
\hline & Self-employed & 290 & 407,866 & 50.1 & 49.1 & 51.0 \\
\hline \multicolumn{2}{|c|}{ Works at home at least some of the time } & 263 & 360,363 & 65.7 & 64.6 & 66.8 \\
\hline
\end{tabular}

Children aged 0-5 only

\begin{tabular}{|c|c|c|c|c|}
\hline & Weighted & & & \\
\hline $\mathrm{N}$ & $\mathrm{N}$ & $\%$ & LOWER & UPPER \\
\hline 1417 & $2,058,368$ & 59.0 & 58.5 & 59.4 \\
\hline 73 & 26,371 & 63.8 & 61.8 & 65.7 \\
\hline 32 & 6,407 & 68.9 & 66.0 & 71.6 \\
\hline 58 & 43,356 & 61.1 & 58.9 & 63.2 \\
\hline 70 & 46,308 & 64.1 & 62.1 & 66.1 \\
\hline 318 & 590,981 & 74.1 & 73.2 & 75.0 \\
\hline 373 & 751,690 & 56.7 & 55.8 & 57.5 \\
\hline 65 & 47,267 & 43.3 & 41.6 & 45.1 \\
\hline 84 & 63,273 & 59.5 & 57.8 & 61.3 \\
\hline 207 & 237,366 & 49.5 & 48.5 & 50.6 \\
\hline 137 & 245,348 & 51.3 & 50.0 & 52.7 \\
\hline 98 & 100,905 & 62.9 & 60.7 & 65.1 \\
\hline 1254 & $1,903,325$ & 58.4 & 57.9 & 58.9 \\
\hline 65 & 54,138 & 75.7 & 73.2 & 78.0 \\
\hline 569 & 825,390 & 64.7 & 63.9 & 65.5 \\
\hline 785 & $1,137,270$ & 58.6 & 57.9 & 59.2 \\
\hline 55 & 82,846 & 33.6 & 31.9 & 35.4 \\
\hline 51 & 54,067 & 44.0 & 41.6 & 46.4 \\
\hline 194 & 336,969 & 44.4 & 43.4 & 45.5 \\
\hline 1113 & $1,607,242$ & 65.8 & 65.2 & 66.3 \\
\hline 1205 & $1,752,475$ & 65.6 & 65.1 & 66.1 \\
\hline 1119 & $1,606,002$ & 64.9 & 64.3 & 65.4 \\
\hline 182 & 281,211 & 59.0 & 57.7 & 60.3 \\
\hline 160 & 232,882 & 74.7 & 73.4 & 76.0 \\
\hline
\end{tabular}




\begin{tabular}{|c|c|c|c|c|c|c|c|c|c|c|c|}
\hline \multirow[t]{4}{*}{ Type of work } & Regular & 1594 & $2,176,451$ & 61.0 & 60.6 & 61.5 & 989 & $1,430,003$ & 65.6 & 65.0 & 66.2 \\
\hline & Seasonal & 36 & 36,777 & 39.9 & 37.3 & 42.5 & 26 & 27,062 & 51.1 & 47.5 & 54.8 \\
\hline & Term & 80 & 110,715 & 56.6 & 54.5 & 58.7 & 57 & 83,632 & 60.5 & 57.8 & 63.2 \\
\hline & On call & 72 & 90,034 & 56.6 & 54.5 & 58.7 & 46 & 63,832 & 64.7 & 62.1 & 67.2 \\
\hline \multirow[t]{4}{*}{ Hours work per week } & Less than 10 & 36 & 48,508 & 50.0 & 47.4 & 52.6 & 25 & 34,329 & 57.1 & 54.0 & 60.1 \\
\hline & 10 -less than 20 & 69 & 101,871 & 54.9 & 52.9 & 56.9 & 50 & 83,565 & 69.0 & 66.6 & 71.4 \\
\hline & 20 -less than 30 & 130 & 159,516 & 53.1 & 51.7 & 54.5 & 77 & 96,019 & 57.5 & 55.5 & 59.4 \\
\hline & More than 30 & 1775 & $2,439,276$ & 60.0 & 59.6 & 60.4 & 1106 & $1,619,525$ & 65.3 & 64.8 & 65.9 \\
\hline \multicolumn{2}{|c|}{$\begin{array}{l}\text { Worked less than } 30 \text { hrs per week because of child care } \\
\text { responsibilities }\end{array}$} & 110 & 150,363 & 50.0 & 48.4 & 51.5 & & & & & \\
\hline \multirow[t]{2}{*}{ Schedule } & Regular & 1503 & $2,058,256$ & 60.1 & 59.7 & 60.6 & 945 & $1,376,465$ & 66.3 & 65.7 & 66.9 \\
\hline & $\begin{array}{l}\text { Irregular (e.g., night shift, } \\
\text { rotating shift) }\end{array}$ & 519 & 704,114 & 56.1 & 55.3 & 56.9 & 321 & 466,771 & 60.7 & 59.7 & 61.7 \\
\hline
\end{tabular}

Source: General Social Survey 2011, T1FF linked file, Statistics Canada 


\section{Table 2. Proportion of Canadian parents living in the provinces who were working* and using child care}

\begin{tabular}{|c|c|c|c|c|c|c|c|c|}
\hline & & $\mathrm{N}$ & Weighted N & $\%$ & LOWER & UPPER & & \\
\hline Any child care & & & & & & & $\chi^{2}$ & $\mathrm{p}$ \\
\hline \multirow[t]{2}{*}{ Type of job } & Paid worker & 1257 & $1,701,456$ & 69.9 & 69.4 & 70.5 & 266.2 & $<.001$ \\
\hline & Self-employed & 180 & 244,349 & 54.3 & 53.0 & 55.5 & & \\
\hline \multirow[t]{4}{*}{ Type of work } & Regular & 1164 & $1,574,759$ & 70.0 & 69.5 & 70.6 & 45.4 & $<.001$ \\
\hline & Seasonal & 15 & 17,157 & 44.4 & 40.0 & 48.9 & & \\
\hline & Term & 50 & 73,978 & 78.5 & 76.2 & 80.6 & & \\
\hline & On call & 29 & 36,514 & 66.9 & 63.8 & 70.0 & & \\
\hline \multirow[t]{4}{*}{ Hours work per week } & Less than 10 & & & & & & 72.9 & $<.001$ \\
\hline & 10-less than 20 & 28 & 37,011 & 60.4 & 56.8 & 63.8 & & \\
\hline & 20-less than 30 & 78 & 97,025 & 55.3 & 53.5 & 57.1 & & \\
\hline & More than 30 & 1310 & $1,783,219$ & 68.4 & 67.9 & 68.9 & & \\
\hline \multirow[t]{2}{*}{ Schedule } & Regular & 1109 & $1,517,391$ & 69.4 & 68.9 & 69.9 & 172 & $<.001$ \\
\hline & $\begin{array}{l}\text { Irregular (e.g., night shift, } \\
\text { rotating shift) }\end{array}$ & 329 & 429,367 & 61.3 & 60.2 & 62.4 & & \\
\hline \multirow[t]{2}{*}{ Spouse type of job } & Paid worker & 1162 & $1,603,226$ & 69.6 & 69.1 & 70.1 & 153.2 & $<.001$ \\
\hline & Self-employed & 164 & 238,421 & 58.5 & 57.3 & 59.8 & & \\
\hline \multirow[t]{4}{*}{ Spouse hours work per week } & Less than 10 & & & & & & 34.4 & $<.001$ \\
\hline & 10-less than 20 & 24 & 37,330 & 53.6 & 49.7 & 57.4 & & \\
\hline & 20-less than 30 & 88 & 133,583 & 69.2 & 67.3 & 71.0 & & \\
\hline & More than 30 & 1198 & $1,659,248$ & 68.5 & 68.0 & 69.0 & & \\
\hline \multirow[t]{2}{*}{ Spouse schedule } & Regular & 1042 & $1,454,773$ & 69.3 & 68.7 & 69.8 & 86.1 & $<.001$ \\
\hline & $\begin{array}{l}\text { Irregular (e.g., night shift, } \\
\text { rotating shift) }\end{array}$ & 283 & 385,889 & 63.6 & 62.5 & 64.6 & & \\
\hline $\begin{array}{l}\text { Sibling of age for supervision in the } \\
\text { home }\end{array}$ & No & 1149 & $1,563,284$ & 73.6 & 73.1 & 74.1 & $* * * *$ & $<.001$ \\
\hline
\end{tabular}

Children aged $0-5$ only

\begin{tabular}{|c|c|c|c|c|}
\hline \multicolumn{3}{|c|}{ Weighted } & \multirow[b]{2}{*}{ LOWER } & \multirow[b]{2}{*}{ UPPER } \\
\hline $\mathrm{N}$ & $\mathrm{N}$ & $\%$ & & \\
\hline 849 & $1,202,003.3$ & 76.3 & 75.7 & 76.9 \\
\hline 744 & $1,045,424.0$ & 77.9 & 77.2 & 78.6 \\
\hline 105 & $156,579.3$ & 67.1 & 65.5 & 68.7 \\
\hline 676 & $949,904.3$ & 77.4 & 76.7 & 78.1 \\
\hline \multicolumn{5}{|l|}{$x$} \\
\hline 38 & $55,452.7$ & 85.1 & 82.5 & 87.3 \\
\hline 20 & $28,767.0$ & 86.5 & 83.5 & 89.0 \\
\hline \multicolumn{5}{|l|}{$x$} \\
\hline 18 & $27,336.4$ & 79.2 & 74.4 & 83.3 \\
\hline 47 & $58,134.6$ & 67.4 & 64.8 & 69.8 \\
\hline 771 & $1,099,366.7$ & 76.6 & 76.0 & 77.3 \\
\hline 663 & $942,603.2$ & 79.1 & 78.4 & 79.7 \\
\hline 187 & $260,352.6$ & 67.7 & 66.3 & 69.1 \\
\hline 708 & $1,005,780.7$ & 77.4 & 76.7 & 78.1 \\
\hline 98 & $145,078.0$ & 71.2 & 69.6 & 72.8 \\
\hline \multicolumn{5}{|l|}{$x$} \\
\hline 16 & $25,695.3$ & 63.3 & 57.6 & 68.6 \\
\hline 52 & $81,588.3$ & 78.1 & 75.6 & 80.4 \\
\hline 730 & $1,037,757.7$ & 77.3 & 76.6 & 77.9 \\
\hline 635 & $924,816.9$ & 78.7 & 78.0 & 79.4 \\
\hline 170 & $224,719.1$ & 69.5 & 68.2 & 70.9 \\
\hline 782 & $1,111,497.2$ & 76.7 & 76.0 & 77.3 \\
\hline
\end{tabular}


Yes 289

Mean number of weeks worked in

the past year

\author{
No child care
}

Any child care

$628 \quad 934,621 \quad 49.1$

$1433 \quad 1,940,629 \quad 49.5$

$\begin{array}{lll}581 & 867,412 \quad 48.6\end{array}$

$1,838,283 \quad 49.7$

1318

Any child care

628

$934,207 \quad 41,3$

No child care 1426

$1,933,504 \quad 40.1$

41.0
40.0

41.6

$\begin{array}{lll}574 & 859,738 & 40.3\end{array}$

\section{0}

$\begin{array}{lllll}1312 & 1,831,882 & 39.6 & 39.5 & 39.7\end{array}$

$1312 \quad 1,831,882 \quad 39.6$

Any child care

worked per week

*Sample includes two parent households where both parents are working, and single parents who are working

Source: General Social Survey 2011, T1FF linked file, Statistics Canada

\begin{tabular}{rrrrr}
68 & $91,458.6$ & 72.2 & 69.9 & 74.3 \\
\hline & & & & \\
\hline 219 & $370,458.0$ & 48.5 & 48.3 & 48.8 \\
\hline 848 & $1,200,261.6$ & 49.0 & 48.9 & 49.1 \\
\hline
\end{tabular}

\begin{tabular}{rrrrr}
211 & $353,931.1$ & 47.8 & 47.5 & 48.2 \\
\hline 803 & $1,149,417.5$ & 49.3 & 49.2 & 49.4 \\
\hline 219 & $371,595.6$ & 40.9 & 40.6 & 41.2 \\
\hline 843 & $1,194,891.6$ & 39.9 & 39.7 & 40.0 \\
\hline 206 & $345,698.1$ & 39.2 & 38.8 & 39.6 \\
\hline 799 & $1,145,282.6$ & 39.3 & 39.1 & 39.5 \\
\hline
\end{tabular}


Table 3. Cost of child care for Canadian parents living in the provinces

At least one child 12

Correlation between self-reported and claimed

amount

Compare self-reported cost to claimed amount

$\%$ where the difference is $>\$ 2000$

Child care cost, per year*

Maximum allowable child care costs

Paid more than max amount

$\%$

$\%$

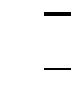

\begin{tabular}{lll}
\multicolumn{3}{c}{ less } \\
\hline$r$ & Mean $\%$ \\
\hline
\end{tabular}

0.58

\begin{tabular}{|c|c|c|}
\hline Amount is same & & \\
\hline Claim is higher & & \\
\hline \multirow[t]{2}{*}{ Self-report is higher } & & \\
\hline & & \\
\hline Self-report & $6,676.49$ & $7,521.29$ \\
\hline Claimed & $3,929.79$ & $4,746.78$ \\
\hline Maximum & $10,342.53$ & $11,871.98$ \\
\hline
\end{tabular}

Self-report

22.7

Claimed

Self-report child care cost but did not claim any
23.7

20.1

71.0

44.8

$4,746.78$

32.6 amount

* among those that report or claim to pay for child care (i.e., > \$0)

Source: General Social Survey 2011, T1FF linked file, Statistics Canada

Note: The lower income parent (including zero) must claim the cc expense although there are

exceptions (including if parent is student) 
Table 4. Description of Canadian parents living in the provinces who self-report child care based on whether or not they make a tax claim

Those who do not make a tax claim

Those who do make a tax claim

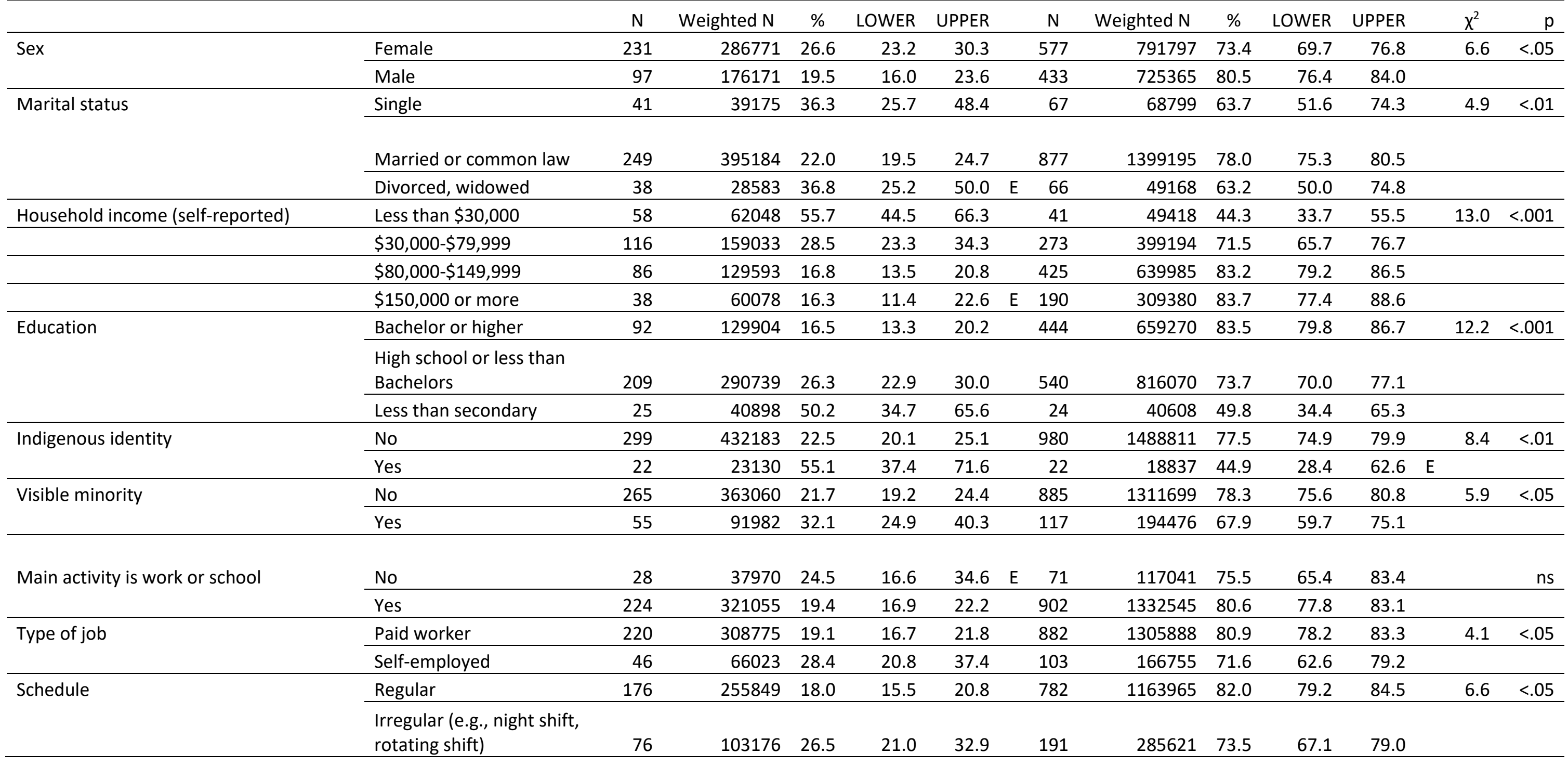


Findlay and Kohen

\begin{tabular}{|c|c|c|c|c|c|c|c|c|c|c|c|c|c|}
\hline \multirow[t]{2}{*}{ Spouse main activity is work or school } & No & 45 & 85286 & 36.5 & 27.2 & 46.9 & 81 & 148233 & 63.5 & 53.1 & 72.8 & 8.6 & $<.01$ \\
\hline & Yes & 223 & 322394 & 20.4 & 17.8 & 23.2 & 823 & 1259042 & 79.6 & 76.8 & 82.2 & & \\
\hline \multirow[t]{2}{*}{ Type of job } & Paid worker & 196 & 294079 & 20.1 & 17.5 & 23.0 & 772 & 1169422 & 79.9 & 77.0 & 82.5 & & $\mathrm{~ns}$ \\
\hline & Self-employed & 42 & 64278 & 26.1 & 18.9 & 35.0 & 103 & 181672 & 73.9 & 65.0 & 81.1 & & \\
\hline \multirow[t]{2}{*}{ Spouse Schedule } & Regular & 155 & 238985 & 17.7 & 15.0 & 20.6 & 719 & 1114275 & 82.3 & 79.4 & 85.0 & 16.2 & $<.001$ \\
\hline & $\begin{array}{l}\text { Irregular (e.g., night shift, } \\
\text { rotating shift) }\end{array}$ & 83 & 118519 & 33.5 & 27.1 & 40.7 & 155 & 234873 & 66.5 & 59.3 & 72.9 & & \\
\hline
\end{tabular}

*Sample includes two parent households where both parents are working, and single parents who are working 
GSS T1FF (parents with children aged 0-11) Weighted

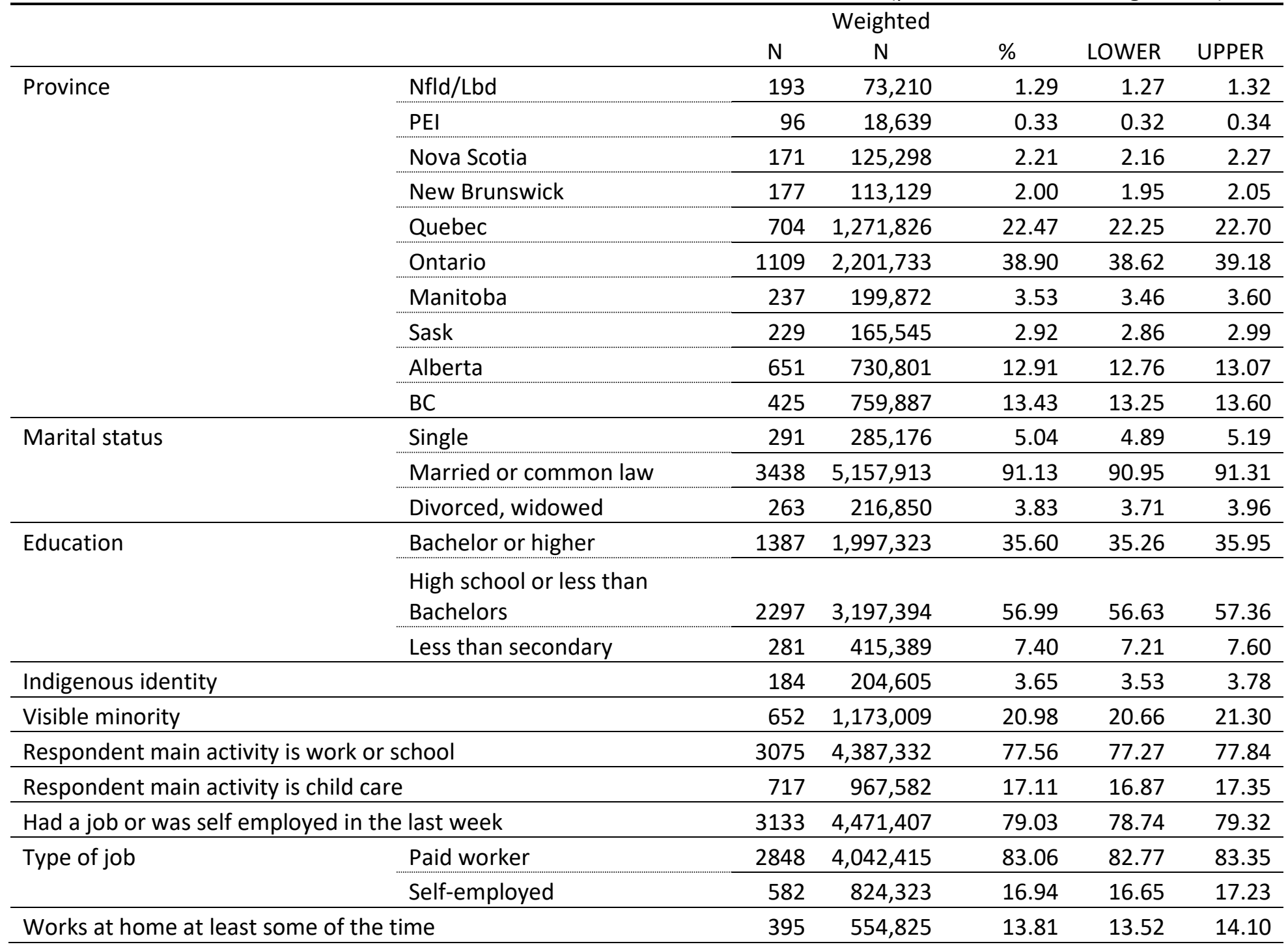

GSS 2011-T1FF (parents with children aged 0-11)

\begin{tabular}{|c|c|c|c|c|}
\hline & Weighted & & & \\
\hline $\mathrm{N}$ & $\mathrm{N}$ & $\%$ & LOWER & UPPER \\
\hline 180 & 75,054 & 1.29 & 1.14 & 1.47 \\
\hline 92 & 21,013 & 0.36 & 0.31 & 0.43 \\
\hline 152 & 133,010 & 2.29 & 1.99 & 2.64 \\
\hline 164 & 116,474 & 2.01 & 1.77 & 2.28 \\
\hline 675 & $1,288,363$ & 22.22 & 21.06 & 23.42 \\
\hline 1032 & $2,249,390$ & 38.79 & 37.33 & 40.27 \\
\hline 223 & 202,995 & 3.50 & 3.15 & 3.88 \\
\hline 210 & 169,527 & 2.92 & 2.61 & 3.28 \\
\hline 617 & 757,758 & 13.07 & 12.29 & 13.88 \\
\hline 390 & 785,433 & 13.54 & 12.60 & 14.54 \\
\hline 259 & 288,853 & 4.98 & 4.26 & 5.82 \\
\hline 3235 & $5,295,930$ & 91.32 & 90.27 & 92.27 \\
\hline 241 & 214,235 & 3.69 & 3.12 & 4.37 \\
\hline 1297 & $2,044,375$ & 35.51 & 33.75 & 37.31 \\
\hline 2159 & $3,288,937$ & 57.13 & 55.30 & 58.94 \\
\hline 258 & 423,590 & 7.36 & 6.37 & 8.48 \\
\hline 168 & 206,064 & 3.59 & 2.95 & 4.35 \\
\hline 593 & $1,170,362$ & 20.43 & 18.86 & 22.09 \\
\hline 2871 & $4,482,281$ & 77.34 & 75.81 & 78.81 \\
\hline 686 & $1,016,593$ & 17.54 & 16.23 & 18.94 \\
\hline 2940 & $4,589,351$ & 79.17 & 77.56 & 80.69 \\
\hline 2675 & $4,154,633$ & 83.19 & 81.65 & 84.62 \\
\hline 542 & 839,760 & 16.81 & 15.38 & 18.35 \\
\hline 373 & 574,503 & 13.91 & 12.50 & 15.44 \\
\hline
\end{tabular}




\begin{tabular}{|c|c|c|c|c|c|c|c|c|c|c|c|}
\hline \multirow[t]{4}{*}{ Type of work } & Regular & 2502 & $3,586,620$ & 88.84 & 88.58 & 89.11 & 2360 & $3,703,821$ & 89.28 & 87.76 & 90.62 \\
\hline & Seasonal & 78 & 92,258 & 2.29 & 2.16 & 2.42 & 69 & 92,866 & 2.24 & 1.67 & 3.00 \\
\hline & Term & 140 & 199,151 & 4.93 & 4.74 & 5.13 & 129 & 193,872 & 4.67 & 3.74 & 5.83 \\
\hline & On call & 125 & 158,986 & 3.94 & 3.78 & 4.10 & 114 & 158,155 & 3.81 & 3.08 & 4.70 \\
\hline \multirow[t]{4}{*}{ Hours work per week } & Less than 10 & 75 & 97,029 & 2.07 & 1.97 & 2.18 & 73 & 103,473 & 2.15 & 1.65 & 2.80 \\
\hline & 10-less than 20 & 126 & 186,962 & 3.99 & 3.84 & 4.15 & 122 & 199,092 & 4.14 & 3.34 & 5.11 \\
\hline & 20 -less than 30 & 241 & 302,338 & 6.45 & 6.27 & 6.64 & 226 & 302,395 & 6.28 & 5.47 & 7.20 \\
\hline & More than 30 & 2847 & $4,097,944$ & 87.48 & 87.23 & 87.73 & 2669 & $4,208,043$ & 87.43 & 86.12 & 88.63 \\
\hline \multicolumn{2}{|c|}{$\begin{array}{l}\text { Worked less than } 30 \mathrm{hrs} \text { per week because of child care } \\
\text { responsibilities }\end{array}$} & 218 & 302,579 & 51.73 & 50.68 & 52.78 & 208 & 311,832 & 51.67 & 45.85 & 57.44 \\
\hline \multirow[t]{2}{*}{ Schedule } & Regular & 2414 & $3,445,917$ & 73.13 & 72.78 & 73.47 & 2274 & $3,556,126$ & 73.53 & 71.61 & 75.36 \\
\hline & $\begin{array}{l}\text { Irregular (e.g., night shift, } \\
\text { rotating shift) }\end{array}$ & 901 & $1,266,378$ & 26.87 & 26.53 & 27.22 & 836 & $1,280,128$ & 26.47 & 24.64 & 28.39 \\
\hline
\end{tabular}

Source: General Social Survey 2011 - T1FF, Statistics Canada 